\title{
Foresight e-Learning Platforms: Insights from a Thai Survey
}

\author{
Poonsri Vate-U-Lan
}

\begin{abstract}
Instant messaging applications on electronic devices such as smart phones and tablet computers is reshaping communication around the globe. This phenomenon is arguably destined to lead to a conduit of prominence and dominance for e-learning delivery. The first objective underpinning this paper was to investigate the behaviour of Thai internet users through data obtained from an extensive online self-administered survey. The second focus was to investigate the level of compliance specifically relating to the internet users' acknowledgement of the "terms of service" which precludes children under thirteen being members or participating. The results that were obtained from 819 survey respondents reinforced the consensus that there was a disturbing misuse of social network applications on mobile devices in particular in terms of overuse. Among the participants, 61.4 per cent were female. Persons aged 11-20 years were the most prominent group of participants $(36.4 \%)$. Persons aged 21-30 years represented 23.9 per cent with the remaining group being over 30 years of age $(39.7 \%)$. Urban and rural respondents were almost balanced $(52 \%$ and $48 \%$ respectively). The findings reconfirmed that surfing social networks was the most popular mobile phone activity for both female and male respondents. This research showed that less than one out of four $(\mathbf{2 3 . 9 \%})$ of Thai internet users knew that a child under 13 was not allowed to apply for a Facebook account. Interestingly, the younger users under the age of 13 years knew that it was illegal to be social network members but the older users were unaware of this regulation. The inconsistencies between each demographic group will be discussed in detail. The research findings reflect numerous and significant complexities that may impact on the digital learning of Thai citizens from numerous perspectives.
\end{abstract}

Index Terms-Behavior of Thai internet users, e-learning platform, internet activities, mobile devices, online survey, social networking.

\section{INTRODUCTION}

The e-learning platforms are the backbone of e-learning strategies given the capacity to successfully simulate orthodox classrooms through the innovative and engaging use of virtual classrooms that induce interaction with students, teachers and can include university input adding another layer of pedagogical and andragogical quality. Social networking, given its instant messaging capacity, has become a technological phenomenon connecting people with ease, especially teenagers. New approaches to online communication are fundamentally revolutionary. The future design of e-learning platforms is likely to become quite flexible and adaptable to the preferred mobile device screen

Manuscript received June 29, 2015; revised October 13, 2015

Poonsri Vate-U-Lan is with Assumption University, Bangkok, Thailand (e-mail: poonsri.vate@gmail.com) activity of potential users. Thus, the first objective of this article was to examine the on screen activity on mobile devices when people were connected to the Internet, thus predicting the future directions of e-learning platforms based on the results from an online self-administered survey in Thailand.

Social networking connects people with fluidity and ease that, negative consequences are emerging [1], [2]. Some people may seek professional treatment because of addiction while others may need help because of cyber-bullying, especially amongst young Internet users [3]-[5]. Social networking has developed as a main online communication conduit not just in Thailand but globally. This leads to the second objective of this current study was to assess the knowledge of Thai Internet users regarding the age restriction stipulated in the "Terms of Service of Facebook" since Facebook is the most popular social networking in 2015 - not only for teenagers in Thailand but also in many other countries [6]-[9]. This represents new information in the field based on original primary research.

\section{RELATED LITERATURE REVIEW}

\section{A. Screen Activities on Mobile Device}

The ubiquitous saturation of mobile devices has brought a new era of computer activity since increasing numbers of people regularly keep their mobile devices nearby, and check them frequently: many carry more than one device. Research in developed countries found a majority of participants (85\%) affirmed that a central part of everyday life is spent on mobile devices [5] and 90 per cent of 18-24 year old respondents to the Thai survey conducted in this research, agreed [10]. The smart phone is a primary driver that has provided seamless opportunities to constantly access the internet; in U.S.A., almost all youth (94\%) surf the net daily on mobile devices and do it constantly [9] while approximately two-thirds of Americans are now smart phone owners, and their devices are a main access device to the internet [11]. Another research firm in U.S.A. collecting data by tracking mobile devices of 470 people found that the average number of hours spent on smartphones was 3.3 hours a day [10]. The most prevalent on-screen activities enacted at least once a day were checking emails (91\%), sending text messages (90\%), searching for online information $(70 \%)$, watching videos or movies $(40 \%)$ and reading (57\%) [10]. Similarly in Australia, smart phones obtained the fastest ownership rate - two-thirds of Australians aged 16 years and older now own this product and their top online activities were conducting a search and accessing social media by getting directions and emailing [12]. Activity 
on smart phones has become more interesting rather than other computer devices since a global business entity can successfully communicate with customers under the $4 \mathrm{Cs}$ media plan strategies, which are classified as: Consistent, Connected, Considered and Concise [13]. Thailand was ranked $7^{\text {th }}$ among countries concerning the most viewers of smart phone screens with a high 167 minutes per day in the research which was conducted across 30 countries representing 70 per cent of the world's population [13]. The highest ranked country of the most viewed smart phone screen activity was Nigeria averaging 193 minutes per day [13]. For indicative comparative purposes the following provides some statistics on usage among you people in various countries. A survey result conducted in an international private university in Thailand, using the internet Addiction Test by Kimberly Young, found that 70 per cent of university students were addicted to the internet-spending more than 25 hours per week [14] or at least 3.7 hours per day on social networking websites [8] with 5.5 hours spent on the internet daily [15]. Philippine users spent 4 hours a day on social media [13] out of 6.3 hours spent on the internet per day [15] which was higher than Belgian teenagers who spent about 2.2 hours online per day [16] while Australian teenagers spent an average 1.2 hours on social network websites per day [12] out of 4.1 hours spent on the internet per day [15].

Spending excessive time engaging in sedentary behaviours such as screen time activities has contributed to problems for children and teenagers [17]. To counter any future problems on computer addiction, Taiwanese lawmakers passed a revision of the Protection of Children and Youths Welfare and Rights Act that bans children under 18 years of age spending excessive or unreasonable time on electronic devices. Taiwanese parents, now obliged under law, can be fined up to US $\$ 2,150$ if found to have allowed their children to use electronic products to an extent that causes them to become ill, either physically or mentally [18].

\section{B. Social Networking Situation on Mobile Devices}

The Facebook Company declared on March 31, 2015 that monthly active users were about 1.44 billion which was about two-thirds of global social networking active users (2.126 billion) [15]-[19]. Almost 90 per cent of Facebook users accessed the social networking site from their mobile devices (1.25 billion or $86.8 \%$ ) [19]. The study detailed huge figures for each second on Facebook: there were eight new users per second, and overall 2,500 messages, and activating 20,000 accounts were sent by users every second [2].

Within the whole population of the Asia Pacific countries (APAC) the average active account of social networking was 27 per cent which was slightly lower than the global figure of 29 per cent while Thailand and Australia were near double (52\% and 56\% respectively) but Singapore recorded the highest (91\%) in APAC [15]. The majority of social network users of APAC were 18-24 years of age while research in North America reports that the use of social networking sites among young adult internet users aged 18-29 jumped from 9 per cent to 49 percent during 2005-2006 [20]. Similar to the U.S. statistic which had over 60 per cent of 13-17 year olds having at least one profile on a social networking site, these groups of users are spending more than two hours per day on social networking sites [21]. According to a quantitative report from an Australian institution, the results from 1,511 interviews (40\% eight to 11 year olds and 60\% 12-17 year olds) showed almost all (95\%) of the eight to 11 year olds accessed the internet [22]. Two thirds of 12-13 year olds $(67 \%)$ had already joined a social networking service and the most popular activity among eight to 11 year olds was playing social networking games (68\%) [22].

The "epidemic" of social network highlights the spread across all ages even though a minimum age to open an account on a social network website has been mandated as 13 years of age - this has been clearly announced and many countries have adopted a law similar to the Children's Online Privacy Protection Act (COPPA) [23]-[25]. According to research conducted with a sample of 467 teenagers between the ages of 13 and 17, many factors especially ownership of mobile technologies and including selected demographic indicators and technology access increase the use of social networking sites by youth [26]. Despite these clearly stated and published age restrictions, large and growing numbers of children 12 years of age and under are using social media networks, often with their parent's knowledge and consent [24]. More than half the children under 13 years of age in the UK with internet access have a profile on a social networking site [27], [28]. Research in the UK, sponsored by the National Society for the Prevention of Cruelty to Children (NSPCC) has found that almost a quarter $(23 \%)$ of 11 and 12 year olds who have a profile on a social networking site say that they have been upset by something that was published [27]. These experiences range from trolling to online stalking to being asked to send a sexual message [27]. While most of these children were able to quickly recover from what they encountered, a disturbing 20 per cent felt upset or scared for weeks or months after the incident [27].

Internet users under 13 years were at risk from many aspects such as cyber bullying, sharing too much information, vulnerability to predatory adults, sharing photos or video they later regret, exposure to large amounts of commercial advertisements which may not be age appropriate, risk of identity theft and reducing the amount of time for physical activity [5]-[21]. Spending time on social network websites cannot create a real relationship - the study by the Pew Research Center found that non-social media users have more close friends; have more trust in people; feel more supported; and are more politically involved in contrast to users active on Facebook [29]. Additionally, a prior exposure on Facebook led to increased arousal during a face-to-face encounter, particularly for those high in social anxiety [30]. Parents and schools can play important roles in guiding children and adolescents to use the internet safely and appropriately by giving them the space to discuss issues freely and guide them to: 1) control information by restricting access to page, 2) secure full name, address, telephone number, social security number and bank or credit card number, 3) post only comfortable information and 4) talk to parents before considering meeting anyone face to face that they have met on line and review the risks involved [21].

In addition, the development of digital literacy should be an integrated and gradated process from elementary school level to ensure that all children receive training in safety skills on 
mobile communication [31]. Many crucial recommendations from the research conducted in Europe emphasised parents' role, school policy and functions of applications [31]. Guardians need to consider and create a friendly approach to make children aware of the risks of social networking sites before signing up for an account. They need to set household rules for accessing social networking sites, monitoring their children's internet usage and limiting their time on websites [5]-[31].

Social networks are not safe places for children since, in practice, social media is open to the delivery of all kinds of information, good and bad, particularly for commercial purposes and with a billion applications [2]. Consequently, more than half of the world internet users are already immersed in this new world. Facebook, as an example, has refused to acknowledge that many of its efforts to block children are not working [23], despite very young users recognized that lots of kids' games were available on Facebook

Thailand has followed the global trend with Facebook as the most popular social network; in 2014, the growth rate of Facebook accounts in Thailand was 53 per cent [8]. More than 28 million Thais (over $42 \%$ of the population) were on Facebook and about half were living in Bangkok (55\%) [8]. A qualitative study conducted in the Philippines confirmed that social media possesses distinct characteristics that are used as a tool by cyber bullies [32]. Other research investigated 256 smart phone Facebook users to determine the factors in the success of Facebook marketing. This research found that advertising messages from close friends only affected consumer brand attitudes, whereas advertising messages provided by commercial sources affect both consumer brand attitudes and purchasing intentions [33]. A research study which examined the motivating factors for playing interactive games on social networks to which 237 people responded found that time flexibility, network externalities and individual gratification influenced people to join a game [34]. Interestingly, e-learning delivered through social networking platforms returned higher positive feedback compared to the normal learning management system when conducted in a teacher training online class [35]. The reasons why e-learning embedded in social networking was successful were freedom of choice and ease of expression, convenience of collaboration, tolerance for global thinking, more openness to diversity, and, above all, positive transformation of learners to become creators [35]. Teenagers familiar with social media communication found it easier to chat to friends of the opposite sex- this was a key research result in a study of international trends among 11-15 year-olds in 30 countries from 2002-2010 [36].

Based on the findings to emerge from this literature review, this research study set itself two main research questions: 1) what onscreen activities on mobile devices do people engage in when connected to the internet? and 2) what are the attitudes of Thai internet users towards the age restriction contained in the "Terms of Service of Facebook"?

\section{RESEARCH METHODOLOGY}

This current study employed an online self-administered survey as the main research instrument. The survey instrument included several sections: demographic information, internet usage behavior, attitudes towards playing computer games and the pattern of onscreen activities on mobile devices. The survey was accessible from across platforms, both personal computers and mobile devices including $\mathrm{iOS}$ and android systems. The invitation to participate was posted on the researcher's social network page and web board for general purposes. It was clearly stated that the research aim was only for academic research purposes with no incentive given. The sample of this current survey was derived by an online convenience sampling method with two reminder invitations after the first announcement.

\section{RESULTS AND DISCUSSION}

A total of 819 participants responded to this online self-administered survey. Each item of the demographic information section and actual questions had different numbers of respondents since participants were free to respond or not to respond. The details of the demographic information are presented in Table I.

TABLE I: PARTICIPANT DEMOGRAPHIC INFORMATION

\begin{tabular}{lll}
\hline \hline Demographic list & Per cent & N \\
\hline Place of living & & \\
Bangkok & 52.0 & 426 \\
Not-Bangkok & 48.0 & 393 \\
Total & $\mathbf{1 0 0}$ & $\mathbf{8 1 9}$ \\
\hline Occupation & & \\
Educator & 33.7 & 276 \\
Secondary School Student & 18.4 & 151 \\
University Student & 33.8 & 277 \\
Other & 14.0 & 115 \\
Total & $\mathbf{1 0 0}$ & $\mathbf{8 1 9}$ \\
\hline Education & & \\
Lower than bachelor degree & 29.5 & 235 \\
Bachelor degree & 37.8 & 301 \\
Post-graduate qualification & 32.7 & 260 \\
Total & $\mathbf{1 0 0}$ & $\mathbf{7 9 6}$ \\
\hline Gender & & \\
Female & 61.1 & 483 \\
Male & 38.9 & 307 \\
Total & $\mathbf{1 0 0}$ & $\mathbf{7 9 0}$ \\
\hline Age & & 1291 \\
11-20 Years old & 37.2 & 63 \\
21-30 Years old & 24.3 & $\mathbf{7 8 3}$ \\
31-40 Years old & 15.7 & \\
41-50 Years old & 13.8 & \\
51-60 Years old & 8.0 & \\
61+ Years old & 1 & \\
Total & & \\
\hline & & \\
\hline
\end{tabular}

Regarding place of residence, the 819 respondents were found to be residing all across the country. Just over half the respondents were residing in Bangkok $(52 \%, n=426)$ while the rest $(48 \%, n=393)$ resided outside the Bangkok area which included the Eastern, Central, North Eastern, Southern, Northern and Western parts of Thailand. Among 819 respondents stated their occupations: about one third were university students $(33.8 \%, n=277)$, teachers or instructors $(33.7 \%, n=276)$, about one in five were secondary school students $(18.4 \%$ or $n=151)$ while the rest selected other 
occupations such as general employers, business person and staff of working in health science area $(14 \%, n=115) .796$ respondents indicated their highest education with 37.8 per cent $(n=301)$ at bachelor degree level and 32.7 per cent $(n=260)$ at post-graduate level while the remaining 29.5 per cent $(n=235)$ were at higher education level. The gender of the 790 respondents was comprised of 483 included females $(61.1 \%)$ and males 307 males (38.9\%). The age profile of the 783 respondents showed the largest group was also the youngest, namely, $11-20$ year olds $(37.2 \%, n=291)$ followed by the 21-30 year olds $(24.3 \%, n=190), 31-40$ year olds (15.7\%, $n=123), 41-50$ year olds $(13.8 \%, n=108), 51-60$ year olds $(8 \%, n=63)$ and older than 61 years $(1 \%, n=8)$.

\section{A. Preferred Screen Activities on Mobile Device}

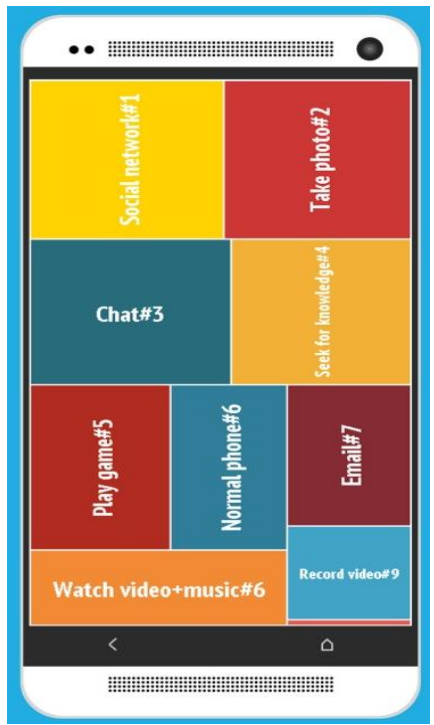

Fig. 1. The on screen activity on mobile devices.

The first question eliciting the list of on screen activities people engage in when their mobile devices are connected to the internet offered 'a check all that apply' which provided various activity options for selection and included an 'other' option of particular activities missing from the list. The results to the first question are presented in Fig. 1. The most frequently chosen mobile phone activities in rank order were found to be surfing on a social network application (79.7\%, $n=507)$, using it as a camera $(77.2 \%, n=491)$, chatting on the "LINE" application $(75.6 \%, n=481)$, surfing for knowledge information $(68.1 \%, n=433)$, playing a computer game $(60.5 \%, n=385)$, watching a video $(50 \%, n=318)$, using it as a normal phone $(50 \%, n=318)$, checking emails $(45.1 \%, n=287)$ and taking a video $(30.3 \%, n=193)$. In addition, the most frequently listed activities indicated under the 'other' option were listening to music, $(n=25)$, working on line, doing internet banking, checking the weather and checking stock market prices. These findings reflected the same trend found by tracking people's screen activities since seven tenths of users preferred to search for online information [10].

These research results reflected similar global trends in screen activity with, as the most popular activity today, being 'stay in a social network' which females access at a higher rate than males [2]. These results also provide a positive hope for e-learning since 'seeking knowledge' was ranked $4^{\text {th }}$ on the list, higher than 'playing games' this seems to suggest that just in time knowledge is more interesting than entertainment activity. Or, in other words, Thai participants engaged in surfing for knowledge rather than just killing time by playing games on their mobile devices.
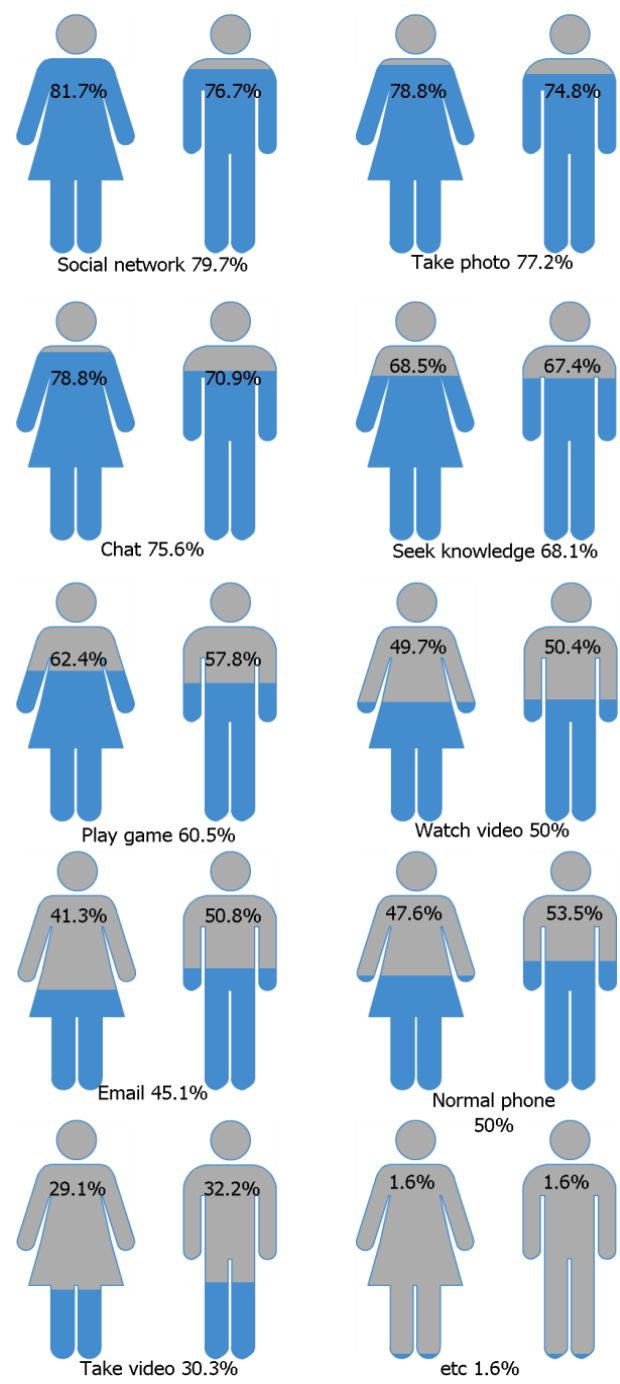

Fig. 2. Comparison on two gender groups of on screen activity on mobile devices.

Fig. 2 presents a comparison of the two gender groups regarding their on screen activity on mobile devices. The format of screen activity on mobile devices of each gender is slightly different. Notably, the biggest difference was that females were higher on 'chatting' $(11.9 \%)$ followed by 'social networking', 'playing games' and 'taking photos' (5\%, $4.6 \%$ and $4 \%$ respectively). On the other hand, males were more active on 'emailing' (9.5\%), 'using a normal phone' and 'taking a video' $(5.9 \%, 3.1 \%$ respectively). Perhaps surprisingly, both genders were almost equal in 'seeking knowledge' and 'watching a video'.

\section{B. Perspective of Facebook's Restriction of Minimum Age}

The second question concerned the attitudes of Thai internet users towards the age restriction in "Terms of Service of Facebook". It was framed as a simple question with four multiple choice answers: a) 13 years old, b) 15 years old, c) no minimum age and d) do not know. The correct answer is (a) 13 years old. There were 796 responses providing information about "acknowledgement of the minimum age for being a Facebook member". The findings revealed only about 
a quarter knew that in the "Terms of Service" 13 years old is the minimum age for Facebook membership $(23.9 \%, n=190)$. In other words, three out of four of social network users do not know the minimum age for using Facebook. The findings showed that over three quarters of participants selected the wrong option or simply did not know $(76.1 \%, n=606)$. Almost two fifths of respondents wrongly thought that there is no minimum age for being a Facebook member $(38.7 \%, n=308)$. Just under a quarter of respondents misunderstood that 15 years of age was the minimum age $(24.4 \%, n=194)$. The smallest group of respondents accepted that they did not know about the minimum age for being Facebook members (13.1\%, $n=104)$. Remarkably, many people indicated in the open-ended question that they just guessed at the seeming most likely answer when they knew they did not know that Facebook's terms of service stipulates a minimum. Thus, this can imply that the actual number of users knowing the actual minimum age is one requirement that should be less.

Further analysis showed little difference between males and females on knowledge of the minimum age (see Fig. 3). Comparing educational background, more bachelor degree users were aware of it but the differences were not large and nor was there much difference between urban and rural users.

Remarkably, when comparing the age cohorts, it was found that more of the younger respondents knew the restriction, especially the 11-20 year group, while users older than 61 years simply did not know. Comparing occupational groups, more secondary school students knew than other groups. In other words, the users under 13 years among the secondary school students were aware of the age restriction regarding membership in the social network already but they also did not respect it. Notably, only one fifth $(20.9 \%)$ of the educator group knew of this important requirement. This can cause a problem since the leader of the classroom or community should be a guardian in loco parentis who informs students under 13 years of age to not join social networking. But in this case this crucial rule has never been announced formally in Thai society. The reason for this might be because of naive thinking about computer and internet technology as occurred in others developed countries [5]-[31].

In summary, lack of knowledge of Facebook's account restriction on the minimum age amongst these Thai respondents would seem to fall into the risk zone since approximately three quarters of these internet users participating in this survey did not know nor were seemingly concerned. From a legal perspective, notification of the restriction has not been publicly disseminated. This risk is amplified since educators who deal with children under 13 years do not have clear knowledge in order to increase awareness and develop a smart internet policy at school.

\section{Predicting e-Learning Platform}

According to the research findings documenting the patterns of on screen mobile activity, it clearly reflects the trends of internet technologies use that impact on the new and changing forms of online two-way communication. The contemporary modes of online two-way communication have empowered internet users to use instant messaging in various forms. People preferred of posting their thoughts or comments in the form of short or long messages, photos, videos and emotional stickers, selecting 'like' or 'unlike' to any opinions, news, photos, videos and other formats of media, sharing what others post, and creating their own community to exchange their interests. Other areas included playing games that need collaboration from the community and participating in any application available on social networking reflecting their own interests. Each of these interaction formats as having the potential to add a set of new functions to future e-learning platforms as they simulate effective communication and flexibility that encourage students to engage and learn more in an online academic environment.

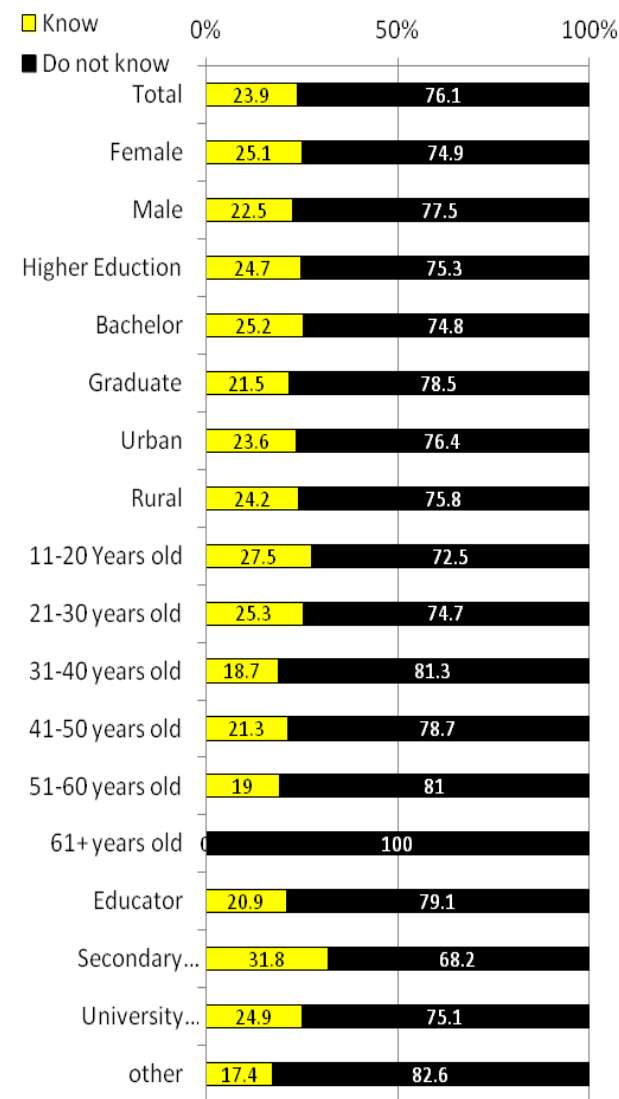

Fig. 3. Group knowledge of Facebook's restriction on minimum age.

In reference to the current findings in Fig. 2, this research has generated six recommendations. Firstly, e-learning platforms should be designed to create a user friendly atmosphere much the same as social networking. Secondly, the students' assignments and participation should be designed to encourage utilization of photos for storytelling or expressing their ideas. Thirdly, 'chatting' should be an interactive discussion which creates more opportunities for both students and teachers. Fourthly, searching for updated information on the internet should be implemented more with an online learning approach. Fifth, 'Games' and applications should be a common online learning activity. Lastly, a task of watching videos and sharing videos should be prevalent and well-practiced in an e-learning environment as its common in today's informal learning.

\section{CONCLUSION AND SUGGESTION FOR FUTURE RESEARCH}

Social networking technologies have increased in terms of 
popularity, potential and scope since the advent of internet access on mobile devices. Each component of the social network draws a new pattern of online two-way communication which quite effectively influences an approach whereby people interact more with each other. This research paper has attempted to disseminate the idea of a new structure of e-learning platforms that include more attractive and effective strategies by examining the preferred activities of contemporary internet users. Both in theory and practice, the idea of delivering e-learning with functions and graphic user interface of social networking is still far from being a certain expectation. One reflection upon the results seems to be that the current e-learning platforms do not seem to be able to convince students to actually enjoy studying online and it has never been designated to be a daily activity. Students choose to be in their favourite social networking from inside since this is where their comfort zone is anchored. Another recommendation for the future of e-learning platforms that can be significantly improved is the recommendation to stay within the same social networking zone being the students' communities; do not be distant from student's online life and be sure to incorporate more games and applications into the online curriculum. Future study of internet activity should consider a triangular research design by combining three ways of eliciting the same data such as surveying, tracking and interviewing. One of the highlights of this research was its gender perspective in the use of computer technology which seems to have narrowed compared with previous studies. The most significant outcome from this research regards the need for expanded strategies to prevent young children being threatened by social networking technology. This is a priority for all, not just schools but also parents and users themselves to consider using technology wisely and appropriately. Children must develop in a balanced online and offline environment that is safe and secure.

\section{REFERENCES}

[1] Statista. (June 2015). Social networks: Global sites ranked by users 2015 | Statistic. The Statistics Portal. [Online]. Available: http://www.statista.com/statistics/272014/global-social-networks-ran ked-by-number-of-users/

[2] J. Bullas, "21 awesome Facebook facts and statistics you need to check out," Jeffbullas's Blog, 2015.

[3] M. Vichienwanitchkul, "Online marketing Thailand: The state of social media," Digital Advertising Association of Thailand, Jan. 2015 .

[4] M. Duggan, N. B. Ellison, C. Lampe, A. Lenhart, and M. Madden, "Social media update 2014," Pew Research Center: Internet, Science \& Tech, 2015.

[5] GfK Bluemoon, "Like, post, share: Young Australians' experience of social media qualitative research report," The Australian Communications and Media Authority, Australia, Aug. 2011.

[6] S. Sakawee, "Thailand social media stats: 28 million on Facebook, 4.5 million on Twitter, 1.7 million on Instagram," Tech in Asia, 2014. .

[7] S. Sakawee, "Thais Are Even More Addicted to Social Media This Year, Research Shows," Tech in Asia, 2013.

[8] Zocial, Inc., "Thailand \& global social media movement 2013-14," 2014.

[9] A. Lenhart and D. Page, "Teens, social media \& technology overview 2015 smartphones facilitate shifts in communication landscape for teens," Pew Research Center, Apr. 2015.

[10] Salesforce, "2014 mobile behavior report," Salesforce Marketing Cloud, 2015.

[11] A. Smith, "U.S. Smartphone use in 2015," Pew Research Center, USA, Internet, Science \& Tech, Apr. 2015.
[12] Regional TAM, OzTAM, and Nielsen, "Q1 2015 Australian multi-screen report," Regional TAM , OzTAM and Nielsen,, Australia, Jun. 2015.

[13] M. Brown. (2014). Adreaction Marketing in a multiscreen world. [Online]. Available: http://www.millwardbrown.com/AdReaction/2014

[14] T. Park, "Dark side of social media; The new drug for new generation, are they addicted?" in Proc. 1st Mae Fah Luang University International Conference 2012, Chiangrai, Thailand, 2012, pp. 1-9.

[15] We Are Social Singapore, "Digital, social \& mobile in APAC in 2015," Mar. 2015.

[16] R. Cock, J. Vangeel, A. Klein, P. Minotte, O. Rosas, and G.-J Meerkerk, "Compulsive use of social networking sites in Belgium: Prevalence, profile, and the role of attitude toward work and school," Cyberpsychology Behav. Soc. Netw., vol. 17, no. 3, pp. 166-171, Oct. 2013.

[17] J. F. Sallis, "Sedentary behaviors and youth: Current trends and the impact on health," Act. Living Res., pp. 1-12, 2014.

[18] H. L. Seok, "Taiwan revises law to restrict amount of time children spend on electronic devices," The Straits Times, 2015.

[19] M. Zuckerberg, "Company info | Facebook newsroom," Facebook, Mar. 2015.

[20] Pew Research Center, "Social networking fact sheet," Social Networking Fact Sheet by Pew Research Center, 2014.

[21] American Academy of Child Adolescent Psychiatry. (Nov. 2011). Facts for families: Children and social networking. [Online]. Available: http://www.aacap.org/App_Themes/AACAP/docs/facts_for_families/ 100_children_and_social_networking.pdf/App_Themes/AACAP/doc s/facts_for_families/100_children_and_social_networking.pdf

[22] GfK Bluemoon, "Like, post, share: Young Australians' experience of social media quantitative research report," The Australian Communications and Media Authority, Australia, 2013.

[23] The 5 million kids who aren't suppose to be on Facebook. The Huffington Post. [Online]. Available: http://www.huffingtonpost.com/2012/09/19/under-13-year-olds-on-fa cebook_n_1898560.html

[24] D. Graber, "3 reasons why social media age restrictions matter," The Huffington Post, 2014

[25] R. Williams, "Children using social networks underage 'exposes them to danger,", 2014.

[26] D. P. Cingel, A. R. Lauricella, E. Wartella, and A. Conway, "Predicting social networking site use and online communication practices among adolescents: The role of access and device ownership," Media Commun., vol. 2, no. 2, pp. 28-38, Jun. 2014.

[27] C. Lilley and R. Ball, "Younger children and social networking sites: A blind spot," National Society for the Prevention of Cruelty to Children, 2013.

[28] Knowthenet, "Kids not equipped for coming of digital age at nine," United Kingdom, Internet, 2014.

[29] K. Hampton, L. Rainie, W. Lu, I. Shin, and K. Purcell, "Social media and the cost of caring," Pew Research Center's Internet \& American Life Project, 2015.

[30] S. M. Rauch, C. Strobel, M. Bella, Z. Odachowski, and C. Bloom, "Face to face versus Facebook: Does exposure to social networking web sites augment or attenuate physiological arousal among the socially anxious?," Cyberpsychology Behav. Soc. Netw., vol. 17, no. 3 , pp. 187-190, Nov. 2013

[31] M. Barbovschi, B. O’Neill, A. Velicu, and G. Mascheroni, "Net children go mobile: Policy recommendations," Policy Recommendations, May 2014.

[32] R. H. Gonzales, "Social media as a channel and its implications on cyber bullying," DLSU Research Congress 2014, De La Salle University, Manila, Philippines, 2014.

[33] T. Yang, "The decision behavior of Facebook users," J. Comput. Inf. Syst., vol. 52, no. 3, pp. 50-59, Spring 2012.

[34] P.-S. Wei and H.-P. Lu, "Why do people play mobile social games? An examination of network externalities and of uses and gratifications," Internet Res. Emerald Group Publ. Ltd., vol. 24, no. 3, pp. 313-331, Jun. 2013.

[35] H. Teräs, M. Myllylä, and M. Teräs, "Empowering teachers to meet the digital native learners," presented at International eLearning Conference 2011, Bangkok, Thailand, 2011.

[36] M. Boniel-Nissim, M. Lenzi, E. Zsiros, M. G. Matos, R. Gommans, Y. Harel-Fisch, A. Djalovski, and W. van der Sluijs, "International trends in electronic media communication among 11- to 15-year-olds in 30 countries from 2002 to 2010: Association with ease of communication with friends of the opposite sex," Eur. J. Public Health, vol. 25, no. Supplement 2, pp. 41-45, 2015. 


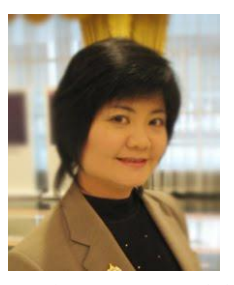

Poonsri Vate-U-Lan was born in Bangkok, Thailand. She completed a master of education in educationa technology in 2000, from Srinakharinwirot University, Bangkok, Thailand and completed the doctor of education in internet-based survey design in 2007

from School of Global Studies, Social Science and

Planning, the Royal Melbourne Institute of Technology University, Victoria, Australia.

She was a visiting international scholar in 2002 working at the Communications and Information Technology Group Laboratory, Faculty of Applied Health Science, Brock University St. Catherines, Ontario, Canada. Currently, she is working as an assistant program director of Ph.D. in e-learning methodology program, Graduate School of e-Learning at
Assumption University of Thailand. Previous article was 'Transforming classrooms through game-based learning: A feasibility study in a developing country'. International Journal of Game-Based Learning. She was a translator of "Don't make me think: A Common Sense Approach to Web Usability" written by Steve Krug into Thai Bangkok, SE-ED, 2002. Her current research interests were e-learning, augmented reality, gamification, social networking for education and computer vision syndrome.

Dr. Vate-U-Lan is a committee member in a Foundation of Prof. Mom Luang Pin Malakul under the patronage of Her Royal Highness Princess Maha Chakri Sirindhorn. In 2011, she won a research grant award for development of an augmented reality book by Bangkok Metropolitan Administration School Board, Bangkok, Thailand. 